\title{
Reading Teaching Application Research on the stage of University
}

\author{
Kai Liu ${ }^{[1]}$ Wen Zhou ${ }^{[2]}$ \\ ( [1]Yunnan college of foreign affairs foreign language yunnan-kunming 651700
}

[2]Kunming university of science and technology Oxbridge college yunnan.kunming 650106 )

\section{Keywords: Reading aloud; Dilemma; Application}

\begin{abstract}
With the need of the development of the society, university teaching methods are changing, teaching method gradually changing into pictures, sound and i colorful nteractive teaching activity. The contemporary college students change from passive learning into active learning to attract attention and stimulate the nerve,so the traditional teaching method reading has gradually been forgotten and abandoned. In this paper, from the basic idea of reading, analysis the dilemma of reading teaching in the University, re-examine and elaborates the reading effect and application in the University teaching, it has certain reference significance for enriching teaching.
\end{abstract}

\section{Reading and reading teaching}

Reading. "Concise dictionary of psychology" to define reading : "reading is to read the materials through the speech organs, and pass information to the brain for understand ". Reading is so-called "loud ly and clearly". Reading is not to see the intuition of word pronunciation, neither nor put simple text to sound, it is oral reproduction and re creation of the text information.Reading ability is closely related to the cultural heritage, accumulation, expression ability and esthetic feeling, it is the comprehensive Humanistic quality of the readers.

Reading Teaching. Reading is not only a kind of reading comprehension, appreciating activities, is also a kind of aesthetic activity and is one of the important content and form of reading skills training. Reading teaching is a complex psychological, physiological change of human to control thelanguage, is a art of audio language, which is based on the understanding of the meaning of the article to accuratelyexpressing the meanings. As reading teaching for college student,it is not only helping students to focus, but also cultivating their understanding of the course content, to explore their potential, increase learning interest, and develop good study habits.

\section{The dilemma of reading teaching in the University}

The distinct features of learning between University and primary and secondary schools, is that the dependent reduction, consciousness enhancement, it requires students to learn by them sevies and innovation,so teachers just speak the focus, difficulties and doubts in the classroom, most of the students learn by their sevies.

University students don't liste. Today's college students, in the material conditions of extremely rich conditions, gradually deviated from the fine tradition of independent thinking and learning. The author made a visual observation in class, found that more than 50 people in a class, about half of all people listen, about 15 notes, 10 people listen and think. A class to be late and leave early, does not focus on the question: do not listen carefully, or simply do not know, before the class did not listen, then one can't understand. The two is about free speech in class, play phone, chat or play games. Three is the number of students in a class to the final text was brand new, never turning marks, waiting for final review and focus, attention, learning initiative and enthusiasm in learning a serious decline, struggling to cope, 60 minutes long live the thoughts spread among the students. Investigate its reason, mainly is the class does not focus, the class did not listen, and review after class, leading to poor learning performance. 
Problems existing in the university classroom reading. Although reading plays an important role in the process of teaching, but in the actual teaching, the students with reading time is less, there are many problems:

No preview before class, do not understand the course content, the sound control ability is poor, can skilled use of reading skills, expressive force is not strong;

The Mandarin is not standard, read will reveal dialect, dialect tone;

To read when the shyness, not full, only to cope with trouble;

To read too little time, did not read aloud in class, not the habit of reading outside the classroom.

Read the teaching difficulties. The traditional concepts of education, University is the advanced stage of education, and the reading is the boy power in Chinese and English teaching, many contemporary college students believe that the university is to read classics, thinking about life, study, read such a low-level way of learning for students is not necessary. University teaching now, in addition to Chinese and English, there is not much the teacher asked the students to read aloud to the collective, individual is less. Main causes of not reading the teaching: teachers don't think it's necessary, students still have to autonomous learning; two is the collective voice, may affect the other teachers teaching; three students are not willing to show in front of the classmates, fear once read the wrong will be ashamed; four is the main College Students think aloud is familiar with the new words and passages, and we can read quite fluently.

The use of the university classroom reading Reading is an important way of teaching.Enable students to concentrate on reading.It can be an effective way to enhance memory, but also the culture of reading and writing skills Reading is an effective method of classroom teaching

You can concentrate on reading, will focus on the classroom.

In class, especially in the morning of course, because some students get up early, deliberately sat in the back began to doze off Using a random sample of individual students the way, so that students can identify with.

Other students in reading when they will be carefully read, students worried pumped myself, so carefully read the contents, and then concentrate

Reading can strengthen classroom discipline.Visual, according to the author $30 \%$ of the students in class is serious in the study purpose and listen to the teacher carefully.Some students listen to occasionally, some of the students is of check on work attendance, waiting for the final time to highlight $~$ So part of the students behave absent-minded in class, often with the surrounding classmates whispered, not only they don't learn can also affect the other students listen and think.Students read, the other students will see read correctly, so as to keep the classroom quiet and order.

Reading aloud can make the students pay attention to the teaching material, read its contents. When some classmates in reading, the other students often follow. The two aspects of the influence on students,

A comparative psychology is the students' union, think that if I could be better than he reads; Second, can cause the student to the teaching material seriously, some students even a semester to buy a textbook.

Reading aloud can increase memory and comprehension.Memory is a special function of the human brain, is an important way of storing human knowledge Reading ability to deepen and consolidate memories, can arouse people's perception and imagination, association memory effect.It by phonological tone change can produce a series of sound image, and make it firmly into the mind of the public.It through the coordination of the organ such as visual hearing sound activity, convey information to the storage areas of the brain, thereby enhance memory and understanding ability.

Reading aloud can keep the attention of students Famous university in the UK competition is intense, people think that college students will be focused on schoolwork instead.But studies have shown that British students concentrate on average only about 10 minutes, and many students because of the need to earn money, so absent in severe cases. In China, according to the sampling 
survey that in the college students surveyed college students in the classroom to concentrate on the proportion of $58 \%$, middle school students in the class, can concentrate was $75 \%$, college students was $17 \%$ lower than the rate for middle school students, daydreaming is common phenomenon in the university classroom.45 minutes for a course, students are required to completely impossible to maintain attention. Especially some mathematical class discipline, no story and plot, sounds more boring, students didn't concentrating will disconnect.

The author in teaching of statistics for this course, when it comes to national economic accounting section, the most began to smoke a classmate to read one paragraph. Who suffered a pause in reading, read wrong, or don't know the word, the other students will laugh, tongue-tied finally finished.Afterwards know just know that they never read aloud in class, don't read.Smoke since I started reading, students focus and increase the interactions between teachers and students.

Skillful application of reading aloud in the college classroom

While reading plays an important role in teaching in university, but need teachers on schedule and use situation, reasonable arrangement, in order to achieve good teaching effect.

On the arrange students to read, to be carefully chosen. As some difficult to understand the content of the need to explain the concept of statements a long paragraph, don't know the words, when the students to read may make a mistake, lead to anaerobic read emotions, even reading, students also do not understand and memory. So teachers should carefully choose suitable for students to read the contents of, such as some of the institutionalized, organized, and strong normative theory, case or a small story, read up generally do not need to explain, it is easy to make students have a profound memory and understanding, to achieve the effect of get twice the result with half the effort.

To read aloud in class to be targeted and selectivity.,interactive teaching method is to give full play to the teachers and students two subjective initiative teaching method, not only can make the students to stay focused, listening, and the teacher will be boring textbook content into a rich and colorful interactive form, so that the students are happy to accept, to achieve good teaching effect. Reading is also one of the interactive teaching content, in the classroom, students choose to read, to targeted and selectivity, one is, according to the classroom situation, timely arrange content to let the students read aloud. Middle or later period such as a class, the students' interest and attention began to decline, randomly selected students in reading, sudden change of classroom atmosphere, often can stimulate students' interest, thus active classroom atmosphere and keep the attention of the lectures. The second, according to the classroom situation, asked the nap, playing mobile students to read aloud. Individual students' attention at the beginning, don't listen to the teacher attentively, at this time, require such students stood up to read aloud, help them stay awake. The practice has proved that this student is pumped reflection, often not doze off, can better keep quiet. The third ,the content of the reading should be suitable for students. Although the teacher has carried on the careful preparation, but in the actual teaching, still should pay attention to the choice of the content. Boys usually prepare less, for example, when choosing content can ask them to read the content of the short, simple content helps them on course to increase confidence. Some complex or statement longer length or paragraph, you need to learn better, reading fluency of students to read, not only can make better eugenics, and can also drive the inquiry learning together.

The students were reading aloud, if it is found that students read mistake, generally do not correct, in case of a crackdown on student's enthusiasm and passion, but teachers can't no matter. Typically wait until the student finished, the teacher to read the content of the fault or problem node and read or interpretation, make students realize their due to unfamiliar read wrong, not smooth. The teacher didn't say again not read well, students in emotional also easy to accept, heart will also realize that the oneself read wrong, enhanced learning

The completion of the communication after reading, stimulates the student to read the enthusiasm, enhance students' learning interest. Read after the completion of the students, add some positive reviews, such as good, nice, very smooth praise language, stimulate students' interest, also can say some encouragement of language, such as not smooth to refuel, content are not familiar with to read 
more and more efforts, students are encouraged to read more, diligent learning.

Some exercises shall be assigned after class. Such exercises may include transcription of main poi nts and queations for discussion, so as to ensure a better command what is taught in class.

\section{Conclusion}

Faculties shall never cease to reform their teaching methods to cater to needs of society as well as all sorts of students. Certain teaching methods are essential to make the class graphic, colorful and com municative and to motivate students. Take Reading Aloud, by which interaction between teachers an $\mathrm{d}$ students can be strengthened and meanwhile students are encouraged. Yet at present this teaching method is not widely adopted. Relevant studies are only at a starting stage and to be continued.

\section{Reference documentation}

[1] Z . S .You.. Journal of Bijie University. 2011,No.11

[2] Y .Zhang. Language Planning, .2011,NO.12

[3] X. Z Cheni. Bulletin of Chinese Language Teaching.2011. NO.15

[4]H.Yu. Taiyuan Shanxi 2013. NO.13.P.8

[5]Y.S.Wang,.Journal of Changchun University of Science and Technology (Higher Education Edition) .2008. NO.19

[6]J.C.Wang .Journal of Linyi Teachers' College,1992. NO.12

[7] M.C.Xiao. Journal of Hunan Educational Institute. 2000. NO.1 1

[8]H.Wang.Journal of Shanghai Teachers University, 1992. NO.1 2

[9]C.L.Xie..Journal of Wuhan Metallurgical Manager's Institute,.2004 . NO.112

[10]C.M.Han.The Journal of Chifeng Education College. 2001. NO.13 